\title{
PERFIL PRODUTIVO DAS EMPRESAS DE MADEIRA COMPENSADA NO ESTADO DO PARANÁ ${ }^{1}$
}

\author{
Willian Borelli Polzl², Priscilla Falco Klingelfus Polzl ${ }^{3}$, Anadalvo Juazeiro dos Santos ${ }^{4}$ e Romano \\ Timofeiczyk Junior ${ }^{4}$
}

\begin{abstract}
RESUMO - O segmento produtivo da madeira compensada passa por reestruturações mundiais. Este artigo buscou avaliar o desempenho produtivo de empresas paranaenses, bem como sugerir parâmetros de eficiência, os quais podem aumentar a competitividade das empresas. Aqui são avaliados indicadores de eficiência produtiva, obtidos através de amostragem direta em uma parcela significativa de empresas de compensado do Paraná, durante os meses de março a junho de 2002 (42\% das empresas paranaenses) e de março a maio de 2007 (34\% das empresas). Foi observado crescimento na eficiência produtiva de determinados tipos de empresas, principalmente nas empresas de compensados de Pinus. Esse crescimento está baseado no uso mais intensivo da capacidade nominal e não necessariamente na melhoria tecnológica. Outro tipo de empresa que obteve melhorias foi a de compensados para construção civil, impulsionado pelo crescimento desse setor. As demais empresas mantiveram suas produções constantes, mesmo com o crescimento geral da economia brasileira. Assim, através dessas informações é possível embasar e definir estratégias empresariais e setoriais.
\end{abstract}

Palavras-chave: Economia florestal, Administração da produção e Setor florestal.

\section{PRODUCTIVITY OPERATIONS IN PLYWOOD MILLS IN PARANÁ STATE}

\begin{abstract}
Plywood mills have been changing their productive structure worldwide. These changes have also been taking place in Paranás industries. The impacts are measure in this article by production efficiency indicators for two periods: March to July 2002 and March to May 2007. The analyses allowed the conclusions that: only plywood mills that produced plywood using pinewood for exportation are better adapted to globalization. The other plywood mills made products traded in the national market and did not increase their productions, improved or updated production systems. Production indicators can therefore be used to compare manufacturers or plan public or private actions.
\end{abstract}

Keywords: Forest economy, Operations management and Forest sector.

\section{INTRODUÇÃO}

A oferta Brasileira de madeira compensada cresce na ordem de $4 \%$, já a demanda de compensados no mercado interno brasileiro estaria diminuindo anualmente em média $3 \%$. Isso evidencia que a produção de compensados estaria sendo destinada à exportação, a qual teve aumento de 16,5\% entre 2002 e 2007 (FAO, 2004; SECEX, 2008).

Aumento na oferta de compensado de determinado país reduz seu custo total, permitindo que haja ampliação de sua participação em todos os mercados. No caso do Brasil, o crescimento da oferta de compensado elevou sua participação em todos os mercados (OLIVEIRA et al., 2005).

As indústrias dos segmentos madeira e mobiliário e do segmento de papel e celulose possuem importante participação no valor do PIB industrial paranaense, sendo responsáveis, respectivamente, por $4,46 \%$ e $19,16 \%$ do PIB.

Em 2006, as exportações dos produtos da indústria de base florestal ocuparam a terceira posição na pauta das exportações paranaenses, com um valor de cerca

\footnotetext{
${ }^{1}$ Recebido em 27.02.2008 e aceito para publicação em 14.10.2009.

${ }^{2}$ Departamento de Estradas de Rodagem do Estado do Paraná - Ponta Grossa, PR - Brasil. E-mail: <wpolzl@ig.com.br>. ${ }^{3}$ Universidade Tecnológica Federal do Paraná. Email: <wpolzl@ig.com.br>.

${ }^{4}$ Universidade Federal do Paraná, Setor de Ciências Agrárias, Departamento de Economia Rural e Extensão - Curitiba, PR

- Brasil.E-mail: <romano@floresta.ufpr.br>e <ajsantos@floresta.ufpr.br>.
} 
de US\$ 1,4 bilhão, o que correspondeu a aproximadamente $14 \%$ do valor total exportado pelo Paraná. As exportações dos produtos da indústria de base florestal foram somente suplantadas pelas exportações da indústria automobilística e do complexo soja (IPARDES, 2007).

As atividades ligadas à produção e processamento da madeira geram, segundo dados do MTE (2008), cerca de 150.000 empregos diretos, e estima-se em 600 mil o número de empregos indiretos ligados a esse setor no Estado.

O segmento industrial da madeira compensada paranaense produz mais da metade da madeira compensada fabricada no Brasil, sendo anualmente responsável por cerca de US\$400 milhões em exportação, aproximadamente $30 \%$ do valor exportado pelo setor no Estado (IPARDES, 2007) e gerando em torno de 25.000 empregos diretos.

Ainda segundo (PARDES (2007), o setor madeireiro no Paraná esteve durante os anos de 1998 a 2005 oscilando entre o terceiro e o quarto lugar entre os setores industriais mais importantes para o Paraná, levando-se em conta o valor bruto da produção e o valor das exportações.

Neste artigo, buscou-se determinar o comportamento do segmento produtivo da madeira compensada no Paraná, comparando dois anos distintos, bem como avaliar esse desempenho com o obtido pelo segmento no Brasil e com outros setores industriais. Tal avaliação possibilitará melhor entendimento das relações entre causa e consequência, vitais para um melhor planejamento das empresas e órgãos privados e públicos envolvidos.

\section{MATERIAL E MÉTODO}

O método utilizado foi o de amostragem via questionário nas indústrias de madeiras compensadas localizadas no território paranaense, nos períodos de março a junho de 2002 e novamente no período de março a maio de 2007.

Os dados coletados em 2002 tiveram uma amostragem de 50 empresas em 119 existentes no Paraná, e no ano de 2007 a amostragem foi realizada em 30 empresas pertencentes ao mesmo grupo da primeira amostragem e 10 outras empresas, totalizando 40 das 118 existentes. O questionário foi respondido através de e-mail e de visitas pessoais às empresas.

R. Árvore, Viçosa-MG, v.34, n.1, p.189-196, 2010
As empresas amostradas estão distribuídas por todas as áreas produtoras do Estado (todas as mesorregiões geográficas, com exceção das Centroocidental e Noroeste) e abrangendo toda a amplitude de produção.

O tamanho das empresas foi definido em função da produção média dos seis meses anteriores à data das entrevistas. Para facilitar as comparações, foi realizada uma classificação das empresas em pequena, média, grande e muito grande, baseada em Polzl (2002).

Outra estratificação foi utilizada, levando-se em conta o produto fabricado pela empresa, conforme Polzl (2002). Para essa classificação, foram consideradas as informações das empresas quanto ao tipo de produto com maior participação no seu faturamento.

\section{1. Utilização da Capacidade Nominal da Empresa}

A Utilização da Capacidade Nominal da Empresa (UCN), medida em porcentagem, é a relação entre a produção nominal mensal da empresa (ou capacidade de projeto) pela produção efetiva (ou produção real) da mesma empresa, conforme fórmula proposta por Polzl (2002) e Slack (2002), apresentada a seguir:

$$
U C N=\frac{(P n-(P p-P e))}{P n} \times 100
$$

em que: $(\%)$;

$\mathrm{UCN}=$ utilização da capacidade nominal da empresa

$P n=$ produção nominal mensal $\left(\mathrm{m}^{3} / \mathrm{mês}\right)$ (capacidade do projeto);

$$
\begin{aligned}
& P p=\text { perda planejada mensalmente }\left(\mathrm{m}^{3} / \mathrm{mês}\right) ; \mathrm{e} \\
& \left.P e=\text { perda mensal que pode ser evitada ( } \mathrm{m}^{3} / \mathrm{mês}\right) .
\end{aligned}
$$

\subsection{Eficiência no Uso de Matéria-Prima}

A eficiência no uso de matéria-prima (Ep) é a relação entre a produção efetiva mensal dividida pelo somatório do consumo mensal de matéria-prima (lâminas torneadas, lâminas faqueadas, painéis sarrafeados, painéis reconstituídos), conforme a fórmula abaixo, proposta por Polzl (2002) e adaptada de Slack (2002):

$$
E p=\frac{P}{\sum(C l t, C l f, C p s, C p r)} \times 100
$$


em que:

$E p=$ eficiência no uso de matéria prima (\%);

$P=$ produção efetiva mensal da empresa por mês ( $\left.\mathrm{m}^{3} / \mathrm{mês}\right)$ (produção real);

$C l t=$ consumo de lâminas torneadas por empresa (m³/mês);

$C l f=$ consumo de lâminas faqueadas por empresa (m³ês);

$C p s=$ consumo de painéis sarrafeados por empresa ( $\left.\mathrm{m}^{3} / \mathrm{mês}\right) ; \mathrm{e}$

$C p r=$ consumo de painéis reconstituídos por empresa (aglomerado, MDF) ( $\left.\mathrm{m}^{3} / \mathrm{mês}\right)$.

\subsection{Eficiência do Trabalho}

Representa a relação entre a quantidade de funcionários e a produção da empresa e pode ser obtida conforme equação abaixo (IPARDES, 1994; POLZL, 2002).

em que: $\quad E t=\frac{P e}{n}$

$E t=$ eficiência do trabalho ( $\mathrm{m}^{3}$ funcionário/ mês $)$;

$P e=$ produção efetiva da empresa $\left(\mathrm{m}^{3} / \mathrm{mês}\right)$ (produção real); e

$n=$ número de funcionários na folha de pagamento da empresa e terceiros envolvidos na produção da empresa.

\section{RESULTADOS}

\subsection{Número de Empresa e Tamanho das Empresas}

A distribuição das fábricas por tamanho de produção está na Tabela 1 .

Em 2002, foram identificadas no Estado do Paraná 119 fábricas de compensado, número esse muito próximo ao encontrado em 2007, 118 fábricas de compensado efetivamente produzindo. Embora tenha ocorrido o fechamento de cerca de $20 \%$ das empresas em 2002 , ocorreu a abertura de novas empresas, entre o $1^{\circ}$ semestre de 2002 e o $1^{\circ}$ semestre de 2007 . Provavelmente outras empresas existam, mas durante as duas fases de coleta de dados essas empresas ou não produziram compensados ou mantinham apenas em funcionamento a parte administrativa da empresa.

Também, podem ser observados o aumento da quantidade de empresas grandes e o aparecimento de empresas muito grandes, denotando um aumento na concentração de mercado, verificado quando analisada a quantidade produzida das cinco maiores empresas em relação à produção total no Estado. Por essa análise, verificou-se que essas cinco empresas maiores representavam $17,53 \%$ do volume produzido (1,78 milhão $\mathrm{m}^{3}$ ) em 2002 e representavam $23,87 \%$ da produção do Estado em 2006, que foi de 1,91 milhão $\mathrm{m}^{3}$.

\section{a. Turnos de Produção}

A relação entre as empresas quanto ao tipo de compensado produzido e à quantidade de turnos de trabalho é apresentada na Tabela 2.

Comparando a distribuição de empresas que operam com diferentes quantidades de turnos de trabalho em 2002 e 2007, pôde ser observado que, em 2007, as empresas de madeira compensada, utilizaram melhor seus equipamentos, aumentando a jornada de trabalho para mais de um turno, Isso ocorreu, principalmente, nas empresas de compensados para Construção Civil e, especialmente, nas de compensado de Pinus, em que aparecem empresas com o terceiro turno de trabalho.

Convém observar que muitas empresas mantêm os secadores de lâminas ou outras seções da fábrica operando em três turnos de oito ou até quatro turnos de $6 \mathrm{~h}$.

Tabela 1 -Quantidade de fábricas de compensado no Paraná por tamanho da produção mensal. 2002 - 2007. Table 1 - Number of plywood mills in Paraná according to production size classes. 2002 - 2007.

\begin{tabular}{|c|c|c|c|c|c|c|}
\hline \multirow[t]{2}{*}{ Tamanho da Produção } & \multirow{2}{*}{\multicolumn{2}{|c|}{$\begin{array}{l}\text { Intervalo de Classes } \\
\qquad\left(\mathrm{m}^{3} / \mathrm{mês}\right)\end{array}$}} & \multicolumn{4}{|c|}{ Empresas Existentes } \\
\hline & & & 2002 & $\%$ & 2007 & $\%$ \\
\hline Pequena & & $<2.450$ & 91 & 76,47 & 73 & 61,86 \\
\hline Média & 2.451 & 4.900 & 25 & 21,00 & 38 & 32,20 \\
\hline Grande & 4.901 & 9.800 & 3 & 2,53 & 5 & 4,25 \\
\hline Muito grande & $>9.800$ & & & & 2 & 1,69 \\
\hline Total empresas & & & 119 & & 118 & \\
\hline
\end{tabular}


Tabela 2 - Porcentagem das empresas com um, dois ou três turnos de trabalho em relação ao tipo de produto predominante nessas empresas. 2002 e 2007 (\%).

Table 2 - Plywood mills operating with 1, 2 or 3 shiftwork, comparing 2002 and 2007.

\begin{tabular}{lcccc}
\hline Tipo da Produção & \multicolumn{2}{c}{2002} & \multicolumn{2}{c}{2007} \\
\cline { 2 - 5 } & 1 turno & 2 turnos & 1 turno & 2 turnos \\
\hline Pinus & 56,0 & 44,0 & 53,2 & 41,9 \\
Construção & 82,0 & 18,0 & 78,6 & 21,4 \\
Moveleiro & 67,0 & 33,0 & 83,3 & 16,7 \\
Decorativo & 71,0 & 29,0 & 80,0 & 20,0 \\
\hline
\end{tabular}

Em 2002, entre as empresas amostradas produtoras de compensado de Pinus, $44 \%$ trabalhavam com dois turnos de trabalho. Em 2007, entre as empresas de compensado de Pinus, $42 \%$ operaravam com duas jornadas. Independentemente do ano em análise, as empresas de compensados de Pinus possuem a maior proporção de empresas $\operatorname{com} 2^{\circ}$ ou $3^{\circ}$ turnos de trabalho.

Aparentemente, as empresas de compensado moveleiro e decorativo sofreram redução no uso de um segundo turno de produção entre os anos de 2002 e 2007.

\section{b. Utilização da Capacidade Nominal de Produção}

A capacidade nominal de produção é a capacidade teórica que pode ser obtida se todos os equipamentos funcionarem de modo eficiente, conforme planejado pelo fabricante (SLACK, 2002).

A Tabela 3 apresenta a taxa de utilização da capacidade nominal de produção das empresas agrupadas por tipo de produto.

A utilização da capacidade nominal de produção média do segmento em 2002 foi de $80,9 \%$, subindo para $82,3 \%$ em 2007.

Tabela 3 - Utilização da capacidade nominal média das empresas por tipo de produto. 2002 e 2007 (\%).

Table 3 - Full production utilization rate in plywood mills, comparing 2002 and 2007.

\begin{tabular}{lcr}
\hline Tipo de Produto & \multicolumn{2}{c}{$\begin{array}{c}\text { Utilização da } \\
\text { Capacidade Nominal }\end{array}$} \\
\cline { 2 - 3 } & 2002 & 2007 \\
\hline Pinus & 77,0 & 84,2 \\
Construção & 78,0 & 80,5 \\
Moveleiro & 68,0 & 67,0 \\
Decorativo & 88,0 & 86,0 \\
Média do segmento & 80,9 & 82,3 \\
\hline
\end{tabular}

R. Árvore, Viçosa-MG, v.34, n.1, p.189-196, 2010
A taxa de utilização da capacidade nominal de produção foi menor entre as fábricas de compensado moveleiro, com 68\% em 2002 e em 67\% em 2007, um desempenho bastante inferior ao das fábricas dos demais tipos de compensados.

\section{c. Eficiência no Uso da Matéria-Prima}

A eficiência no uso da matéria-prima é uma importante ferramenta para a obtenção da eficiência produtiva, pois, conforme Polzl (2002), a matériaprima corresponde a $55 \%$ dos custos e a cerca de 90\% do peso do compensado. A Tabela 4 apresenta o rendimento produtivo na fabricação de compensados relacionando o tipo de compensado produzido com o ano em análise.

O rendimento no processo de produção da madeira compensada teve pequeno aumentou nos últimos cinco anos em 2002 estava em 85,9\%, e em 2007 foram encontrados $86,8 \%$, aumento de $0,9 \%$.

Todos os quatro tipos de empresas melhoraram o aproveitamento no uso de sua matéria-prima, destacando-se a diminuição em cerca de 3,9\% das perdas no processo produtivo das fábricas de compensado de Moveleiro.

Tabela 4-Eficiência no uso de matéria-prima durante a fabricação de compensados, por tipo de produto fabricado. 2002 e 2007 (\%).

Table 4 - Raw material waste rate in plywood mills, comparing 2002 and 2007.

\begin{tabular}{llr}
\hline Tipo de Produto & \multicolumn{2}{c}{$\begin{array}{c}\text { Eficiência no Uso de } \\
\text { Matéria-Prima }\end{array}$} \\
\cline { 2 - 3 } & 2002 & 2007 \\
\hline Pinus & 85,2 & 86,8 \\
Construção & 84,5 & 85,6 \\
Moveleiro & 83,3 & 87,2 \\
Decorativo & 87,5 & 88,8 \\
Média do segmento & 85,9 & 86,8 \\
\hline
\end{tabular}


Tabela 5 - Eficiência do trabalho nas fábricas de compensado do Paraná, por tipo de produção, 2002 - 2007 ( $\mathrm{m}^{3}$ funcionário/mês).

Table 5 - Work productivity rate in plywood mill, comparing 2002 and 2007.

\begin{tabular}{lcc}
\hline Empresas & \multicolumn{2}{c}{ Produtividade } \\
\cline { 2 - 3 } & 2002 & 2007 \\
\hline Pinus & 13,0 & 13,5 \\
Construção & 6,5 & 6,5 \\
Moveleiro & 9,5 & 9,5 \\
Decorativo & 6,5 & 6,5 \\
Média do segmento & 10,5 & 10,6 \\
\hline
\end{tabular}

\section{d. Eficiência do Trabalho}

A Tabela 5 apresenta a eficiência do trabalho por tipo de produção, definindo quanto cada trabalhador em média produz de compensado por mês. Para tanto, é importante avaliar essa produtividade, observando-se o tipo de compensado fabricado, pois determinados produtos possuem maior tempo de ciclo de produção.

Durante o período de 2002 a 2007, a produtividade do trabalho nas fábricas de compensado não se alterou, de forma que a média ponderada para o segmento permaneceu em torno de $10,5 \mathrm{~m}^{3}$ funcionários/mês.

A produtividade do trabalho nas fábricas de compensado do Paraná foi visivelmente maior nas empresas que fabricavam compensado de Pinus, indiferente do ano analisado. A produtividade nessas empresas foi o dobro da encontrada nas fábricas de compensado para construção civil e decoração.

\section{DISCUSSÃO}

Embora o número de empresas continue o mesmo, a escala de produção delas aumentou; isso pode ser comprovado pelos estudos recentes, que afirmam que a quantidade de madeira compensada produzida pelo Estado do Paraná subiu de $1.780 .000 \mathrm{~m}^{3} \mathrm{em} 2002$ para $2.140 .000 \mathrm{~m}^{3} \mathrm{em} 2004$ e caiu para $1.910 .000 \mathrm{~m}^{3} \mathrm{em} 2006$ (BERGER et al., 2008).

Esse aumento de $20 \%$ na produção física, entre 2002 e 2004, também foi sinalizado para o setor madeireiro paranaense como um todo, o qual teve aumento na produção de 32\% em 2004 (IBGE, 2008).

Parte do aumento da produção efetiva de compensados no Paraná se deveu à desvalorização do real perante o dólar, que no primeiro semestre de
2002 estava em torno de $\mathrm{R} \$ 2,40$, aumentando para mais de $\mathrm{R} \$ 3,00$ entre maio e agosto de 2004, retornando a cerca de $\mathrm{R} \$ 2,00$ no primeiro semestre de 2007 (BCB, 2007). Essa relação entre taxas de câmbio e aumento da produção de compensados foi constatada por Berger et al. (2008).

A produção das empresas de compensados de Pinus é destinada, prioritariamente, à exportação, e os demais tipos de compensados são mais voltados para o mercado interno brasileiro (ABIMCI, 2005). Essa exportação determina exigências diferenciadas em qualidade e produtividade; um exemplo é a exigência de certificação de produto para os compensados exportados.

Essa adequação às necessidades da exportação é exemplificada com a criação do Programa Nacional de Qualidade da Madeira, implantado em meados de 2000, que hoje possui cerca de 10 empresas paranaenses certificadas; da certificação TECO (norteamericana), com nove empresas paranaenses certificadas em 2007 e do Instituto Alemão WKI - Fraunhofer-Institut fuer Holzforschung, Wilhelm-Klauditz-Institut; uma das credenciadas para certificação "CE mark".

Quando comparada a taxa de utilização da capacidade nominal de produção das empresas do segmento da madeira compensada com a média de utilização das indústrias paranaenses, observou-se que em 2002 o segmento era $3,2 \%$ mais efetivo; utilizava $80,9 \%$ contra $77,7 \%$ da média do Estado (MDIC, 2006).

A indústria de compensados para construção civil deve passar por momentos de aquecimento na produção, o que pode ser observado pelo leve aumento na utilização da capacidade nominal de produção, consequência do programa do governo federal de aceleração do crescimento - PAC, que possui políticas de fortalecimento do setor de construção civil, que passou por quase uma década de instabilidade econômica (LOURENÇO, 2007).

As empresas de compensado de Pinus apresentam o maior aumento na utilização da capacidade nominal de produção, muito próximo das empresas de compensado decorativo.

Segundo Polzl (2002), são dois os principais motivos para a melhor utilização da capacidade nominal também pelas empresas de compensado decorativo: devido ao fato de que fabricarem produtos com maior valor agregado e, em geral, possuírem as estruturas produtivas menos defasadas tecnologicamente (empresas tão modernas quanto às de compensados de Pinus).

R. Árvore, Viçosa-MG, v.34, n.1, p.189-196, 2010 
O aumento da produção de compensados destinados à exportação torna as empresas de compensados de Pinus suscetíveis às variações na taxa de câmbio e no preço internacional do compensado, sendo esses limitantes para a maior capacidade de investimentos em tecnologia. Dessa forma, justifica-se que, em um primeiro momento, a resposta das empresas para um mercado mais aquecido seja a de melhor uso da capacidade nominal, para depois, com mercado mais estável ou com reservas próprias, poderem investir em ampliação ou tecnologia. Essa estratégia para o aumento da produção via melhor uso da capacidade nominal é constatada na Tabela 3.

Essa perspectiva também é citada por Lourenço (2007), o qual generalizou, em todas as empresas paranaenses, que a inibição das renovações e ampliações da capacidade nominal é causada pela conjugação entre juros reais elevados; progressiva apreciação cambial; e insuficientes inversões públicas em infraestrutura e financiamentos a setores industriais.

A melhoria no aproveitamento da matéria-prima em todos os tipos de empresa de compensados pode ter diversas explicações, entre elas a subida substancial no preço real da madeira de diâmetros maiores, a qual estava em torno de $\mathrm{R} \$ 61,40$ (diâmetro entre $25 \mathrm{~cm}$ e $35 \mathrm{~cm}$ ) em 2002, subindo para $\mathrm{R} \$ 67,33 \mathrm{em} 2004$ e caindo para R\$65,60 em 2006 (SILVICONSULT, 2007).

Os valores encontrados para o aproveitamento da matéria-prima, em ambos os anos, estão dentro do esperado, conforme o trabalho de Silva (2001 citado por BRAND et al., 2004), realizado em indústrias de compensados de Pinus da Região Sul, o qual constatou que apenas $11 \%$ do resíduo gerado na fabricação de compensado aparece após a laminação das toras.

Também Bonduelle et al. (2004 citados por BRAND et al., 2004) encontraram rendimento médio ponderado nas indústrias de chapas compensadas paranaenses de $89,8 \%$ (durante a manufatura até a esquadrejadeira) e de $95,6 \%$ na lixadeira, totalizando cerca de $14 \%$ de perdas em volume.

Além do aumento no preço da madeira de Pinus, mudanças nas restrições para exploração de espécies nativas da Amazônia podem também ter forçadas as empresas a otimizarem seus rendimentos no uso de matéria-prima.

A melhoria dos indicadores diretamente relacionados com o melhor uso da matéria-prima pode repercutir na maior competitividade do painel compensado frente a outros painéis de madeira reconstituída, pois, como foi constatado por Cabral et al. (2006), os painéis Oriented Strand Board - OSB têm grande potencial de substituição, principalmente para fins estruturais, devido ao fato de serem menos exigentes do que o compensado na qualidade da matéria-prima. Para a fabricação do OSB, é possível utilizar madeiras de qualidade inferior e até resíduos florestais e industriais, desde que estes apresentem dimensões que permitam a confecção dos flocos.

Comparando o custo de produção e preço final no mercado de produtos de madeira reconstituída, percebe-se que, atualmente, o OSB tem maior margem de comercialização do que o compensado. O mesmo aproveitamento de madeiras de menor qualidade e até mesmo resíduos podem ser observados na fabricação de painéis aglomerados e de painéis Medium Density Fiberboard - MDF, ambos para fins moveleiros.

Observando a eficiência do trabalho, podem-se discutir três possíveis causas para a menor produtividade nas empresas de compensados decorativos, moveleiro e para construção civil: 1) as empresas de compensado de Pinus possuem maiores escalas de produção que as demais; 2) estas também têm menor quantidade de atividades necessárias para a produção, não necessitando: preparo intensivo das lâminas em guilhotinas, junção das lâminas da capa e contracapa (construção civil, moveleiro e decorativo); aplicação de acabamentos nas superfícies (construção civil); e 3) aumento da participação de compensados de espessura fina $-4 \mathrm{~mm}$ a $9 \mathrm{~mm}$, os quais têm menor produtividade quando comparados com o mesmo volume de compensados de maior espessura $-15 \mathrm{~mm}$ a $21 \mathrm{~mm}$, típicos de fábricas de compensados de Pinus.

\section{CONCLUSÃO}

A análise da eficiência produtiva permitiu observar dois grupos de empresas de madeira compensada no Paraná, um grupo eficiente e competitivo e outro grupo mais vulnerável a mudanças no mercado consumidor, sendo o primeiro formado por empresas de compensados de Pinus.

Pode-se concluir que o aumento da produção paranaense de madeira compensada, em torno de $6 \%$, se devem, principalmente, ao aumento da escala de produção das empresas de compensado de Pinus; esse aumento na produção gerou, também, aumento no número de empregos, como pode ser observado pela quase inalterada produtividade da mão de obra no período 
e pelo aumento de cerca de 3.000 empregos nas empresas de laminação e compensado entre 2002 e 2006 (crescimento de 12,8\%), segundo MTE (2008).

Também ocorreu o uso mais intensivo dos equipamentos das empresas, verificado pelo aumento no número de turnos de serviço, diminuição das perdas de matéria-prima durante os processos produtivos e, principalmente, pelo aumento do uso da capacidade nominal já instalada.

O crescimento das empresas de compensados para construção civil, durante o último trimestre de 2006 e o primeiro trimestre de 2007, devem-se, principalmente, a fatores externos ao setor florestal, entre eles o aquecimento do setor brasileiro da construção civil, estimado em 5,6\% (IBGE, 2008).

As demais empresas de compensado permanecem estáveis, com características muito similares às de cinco anos atrás, o que é um indicador preocupante, pois o Brasil cresceu em torno de 3,2\% ao ano e $15,89 \%$ no período de 2002 a 2006 (IPEA, 2008).

Com as informações deste estudo, tem-se uma visão mais abrangente do segmento produtivo. Isso auxilia a composição de cenários para o futuro. Cenários esses vitais para a elaboração de estratégias empresariais e setoriais, às quais podem trazer fortalecimento geral ao segmento produtivo como um todo.

\section{REFERÊNCIAS}

\section{ASSOCIAÇÃO BRASILEIRA DA INDÚSTRIA DA MADEIRA PROCESSADA \\ MECANICAMENTE - ABIMCI. Estudo \\ setorial 2004. Curitiba: 2005.}

BANCO CENTRAL DO BRASIL - BCB. Série histórica da taxa de câmbio. Disponível em: <http://www5.bcb.gov.br/pec/taxas/port/ PtaxRPesq.asp?idpai=TXCOTACAO2007> Acessado em: janeiro, 2008.

BERGER, R. B. et al. Oferta e demanda de madeira no estado do Paraná. Curitiba: SETI/ UFPR/ CEFA, 2008. 192p.

BRAND, M. A. et al. Avaliação do processo produtivo de uma indústria de manufatura de painéis por meio do balanço de material e do rendimento da matéria-prima. Revista Árvore, v.28, n.4, p.553-562, 2004.
BRASIL. Ministério do Desenvolvimento, Indústria e Comércio Exterior. Anuário estatístico 2006. Brasília: SDP, 2006. 62p.

BRASIL. Ministério do Trabalho e Emprego. Acompanhamento mensal de postos de trabalho. RAIS. Disponível em <http:// www.mte.gov.br/pdet/Acesso/RaisOnLine.asp>. Acessado em: janeiro, 2008.

CABRAL, C. P. T. et al. Propriedades de chapas tipo OSB, fabricadas com partículas acetiladas de madeiras de Eucalyptus grandis, Eucalyptus urophylla, Eucalyptus cloeziana e Pinus elliottii. Revista Árvore, v.30, n.4, p.659-668, 2006.

INSTITUTO BRASILEIRO DE GEOGRAFIA E ESTATÍSTICA - IBGE. Pesquisa industrial mensal, produção física regional. Disponível em: < http://www.ibge.gov.br/home/ estatistica/indicadores/industria/pimes/ default.shtm>. Acessado em: janeiro, 2008.

\section{INSTITUTO PARANAENSE DE} DESENVOLVIMENTO ECONÔMICO E SOCIAL IPARDES. Competitividade da indústria paranaense: uma análise setorial. Curitiba: 1994. 64 p.

\section{INSTITUTO PARANAENSE DE} DESENVOLVIMENTO ECONÔMICO E SOCIAL IPARDES. Análise conjuntural. Curitiba: 2007. nov./dez., p.32.

INSTITUTO DE PESQUISA ECONOMICA APLICADA - IPEA. Série histórica do produto interno bruto - PIB no Brasil. Disponível em: $<$ http:// www.ipeadata.gov.br/ipeaweb.dll/ MenuCtrl?SessionID=1876754527\&Mod=MACRO $\&$ Lang=Portuguese $>$. Acessado em: janeiro, 2008.

LOURENÇO. G. M. A indústria paranaense em 2006. Análise Conjuntural, v.29, n.1/2, p.5-18, 2007.

ORGANIZAÇÃO DAS NAÇÕES UNIDAS PARAA AGRICULTURA E ALIMENTAÇÃO - FAO Estudio de tendencias $y$ perspectivas del sector forestal en América Latina documento de trabajo: Informe Nacional Brasil, perspectivas para 2020. Roma: 2004.180p.

R. Árvore, Viçosa-MG, v.34, n.1, p.189-196, 2010 
OLIVEIRA, A. D.; RIBEIRO, I. S. A.; SCOLFORO, J. R. S. Análise do mercado internacional de compensado. Revista Árvore, v.29, n.2, p.311320, 2005.

POLZL, W. B. Eficiência produtiva e econômica do segmento industrial da madeira compensada no estado do Paraná. 2002. 114f. Dissertação (Mestrado em Economia Florestal) - Universidade Federal do Paraná, Curitiba, 2002.
SECRETARIADE COMERCIO EXTERIOR - SECEX. Sistema Alice. Disponível em: <http:// aliceweb.desenvolvimento.gov.br/default.asp>. Acesso em: jan. 2008.

SLACK, N.; CHAMBERS, S.; JOHNSTON, R. Administração da produção. 2.ed. São Paulo: Atlas, 2002. 747 p.

Silviconsult. Boletim de Preço de Toras, v.5, n.31, p.1-5, 2007. 